\title{
Suggestion on Promoting Agricultural Insurance in China
}

\author{
Yu Zheng \\ School of Management, Xi'an Polytechnic University \\ 19 Jinhua South Road, Xi' an 710048, China \\ Tel: 86-29-8233-0193_E-mail: zyki2003@163.com
}

Juan Zhang

Applied Technology College, Xi'an Polytechnic University

19 Jinhua South Road, Xi'an 710048, China

Wangxi Wang

China Flight Test Establishment

8 Shifeiyuanlu Road, Xi'an 710089, China

\begin{abstract}
During the practice of agricultural insurance in over 20 years, Chinese agricultural insurance has been facing many problems, i.e. short of legal and political support, insurance awareness, supply and demand etc. In order to promote Chinese agriculture insurance market, we have to adopt relevant measures.
\end{abstract}

Keywords: Chinese agricultural insurance, Problem, Suggestion

\section{Status quo of agricultural insurance in China}

China is an agricultural country. It is also one of the countries which suffer from serious natural calamities. According to statistics report from National Bureau of Statistics of China, the total planting area was 122.08 million hectare, the planting area which has been hit by natural calamities was 38.8 million hectare in 2005, and increased 3.91 million hectare compare to previous year. Frequent natural calamities have brought farmers heavy economic losses. The economic losses which caused by natural calamities was 108 billion Yuan in 2005, and increased 37 billion Yuan compare to previous year. So that develop Chinese agricultural insurance becomes more and more urgent now.

In 80s of 20th century, the Chinese insurance system began to be gradually recovered. Since 1982, civil administration departments, agriculture departments and insurance companies issued agricultural insurances one after the other, it presented fast uptrend. The income of agricultural insurance premium was 862 million Yuan in 1992. At the same time, loss ratio increased largely, the loss ratio of agricultural insurance reached 119\% in 1991. However, along with lessened support from government, especially, when PICC started to change into commercial insurance company, agricultural insurance shrank step by step. In 2000, the income of agricultural insurance premium decreased to 387 million Yuan, and it continuously dropped to 300 million Yuan in 2002. In other words, one farmer paid less than 1 Yuan for insurance at that time. Because of the long deficit of agricultural insurance, insurance companies cancelled agricultural insurances in succession.

Three-Nong Problems have been paid more and more attention recent years, as well as China entered WTO, the sheltering effect of agricultural insurance for agriculture, countryside and farmers becomes prominent, and agricultural policy insurance has been paid attention to. In 2004, the CIRC has launched agricultural insurance experimental units in 9 provinces and cities. The agricultural insurance premium has increased obviously, and the loss ratio has shown a sharp decrease in 2005.

\section{Problems of China's agricultural insurance}

Chinese Agricultural Insurance has been facing many problems which obstruct its development.

1) Agricultural insurance is short of legal and political support. There is no special agricultural insurance law in China. Moreover, the insurance law does not put a clear identity for agricultural insurance. So, the default would cause problem inevitably. 
2) Farmers are lack of insurance awareness in China. Most farmers still do not get used to participate in agricultural insurance. They have fluke mind when face risks. In Fact, some farmers are very poor therefore they cannot bear the premium. It requires government to publicize agricultural insurance among farmers intensively. Moreover, offering more preferential policies for agricultural insurance.

3) The dispersive management of agricultural insurance fund cannot promote the development of agricultural insurance. Usually, insurance companies manage agricultural insurance together with commercial insurance, which cause agricultural insurance fund to be used as a part of property insurance fund, and the profit of property insurance to be used to cover the loss of agricultural insurance. So that agricultural insurance fund is lack of individual account, means check agricultural insurance fund together with other insurance funds. Although some insurance companies have fished out some methods for checking agricultural insurance separately, they still haven't given up using property insurance to support agricultural insurance.

4) Conflicts between supply and demand of the agricultural insurance. On the one hand, the conflicting management aim exists between agricultural insurance and commercial insurance. If operation is commercialized, insurance companies have to bear risks from both nature and market. In order to cover these risks, insurance companies require insureds to pay high premium. As we know, the insureds of agricultural insurance are mostly poor farmers in China, if the agricultural insurance premium is high, insureds can not afford it; if the agricultural insurance premium is low, insurance companies can not maintain their operations. So it leads to blur common benefit between insureds and insurance companies. On the other hand, simplex source of fund restricts the development of agricultural insurance. Nowadays, the fund of agricultural insurance mainly comes from premium which paid by insureds. Agricultural insurance premium is still very high for poor farmers in China. Although agricultural insurance is to protect insureds, and insureds should pay for the premium, but due to low incomes of insureds, only depends on premiums which paid by insureds to aggregate agricultural insurance fund is very difficult. This simplex and unstable source is one of the main reasons caused unsuccessful of agricultural insurance. Furthermore, agricultural insurance coverage has been controlled strictly, and with complex operation, which cause insureds and insurance companies sometimes have large divergence, so usually insureds have to give up to buy agricultural insurance.

5) Unreasonable category structure of agricultural insurance causes unreasonable structure of agricultural insurance fund. Obtaining maximize profit is the aim for insurance companies. Normally, insurance companies prefer to offer agricultural insurances which with high short-term return and low risk. However, they rarely issue long-term insurance, due to its high uncertainty and risk. This causes the unstable of agricultural insurance fund.

Why it shows dead-alive situation in China? The surface reasons are: 1) heavy deficit of agricultural insurance. 2) insurance companies are willing to issue types of risk with high profit, whereas, unwilling to issue types of risk with high management costs and high risk. 3) farmers' low income and lacking insurance awareness cause low cover activity.

In fact, the essential reason which leads to the dead-alive situation is the incomplete system of agricultural insurance in China. For a long time, except the remission of sales tax, there is no other support policy from Chinese government. Agricultural insurances are almost standard commercial insurances. No other than this agricultural insurance system causes the standstill of Chinese agricultural insurance.

\section{Suggestions on developing China's agricultural insurance}

How to develop China's agricultural insurance?

Firstly, strengthen legislation is a key issue. During the development of agricultural insurance, national will plays a leading role. Moreover, grant-in-aid, financial support and tax preference etc. also play great effect. Besides, the aim of agricultural insurance is to promote steady development of agriculture, not with the aim of gaining profit. Therefore, Insurance law which applies to commercial insurance is unsuitable for agricultural insurance. So set up a suitable agricultural insurance law to support Chinese agricultural insurance is very important.

Secondly, due to the simplex source and dispersive management of agricultural insurance fund, set up modern collection and management system for agricultural insurance fund is also very important. At the same time, constitute perfect regulation and policy for agricultural insurance fund, including its collection methods \& instruments, the checking method which different from commercial insurance fund, as well as the ownership \& management right of agricultural insurance fund, so that make it go on the track of institutionalization and law-based.

Thirdly, owing to the impact of environment and paying capacity in different places in China, the gap of insurance capacity is very large, so set legal types of risk for agriculture insurance is very necessary. In terms of law of large numbers, the bigger participation rate of insurance, the bigger stability coefficient, and the more logical. It is possible to set legal types of risks based on the regional difference, for example, Third Party Liability (TPL) in auto insurance. It is helpful to improve people's insurance awareness, increase fund for insurance companies, and steady the management of agricultural insurance. 
Finally, reinsurance is also necessary for crops in order to scatter risks further. The same method of agricultural insurance in Western countries is that use administrative means to constitute multiple reinsurance system. It is possible to be applied in Chinese agricultural insurance. Constitute reinsurance system can improve the activity of agricultural insurance operators, conduct operational emphases, increase the income of handling charge and enhance the management level.

\section{References}

Chen Danli and Zhou Lie. (2006). Empirical Study on the Situation of Agricultural Insurance's Development in China. Southeast University. pp. 12-18.

Du Yankun .(2005). The Basic Thought to Construct Agriculture Policy Insurance System. Economic Information Daily.

Xiao Shengting and Zhang Jingyu. (2007). Research on Agricultural Insurance Modes in China. University of Skovde. pp. 13-19.

Yuan Jianhua. (2008). Study on Models of Policy-rated Agricultural Insurance Company. Modern Finance \& Economics, No. 2, pp. 32-36. 